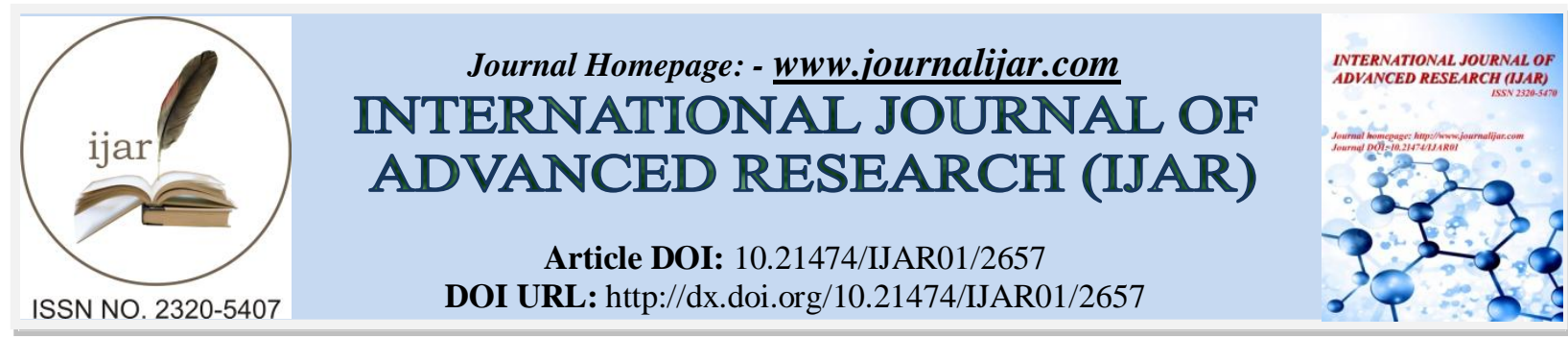

RESEARCH ARTICLE

\title{
ENERGY CHALLENGES IN INDIAN AGRICULTURE.
}

Prof. Dr. Sanjay Kar ${ }^{1}$ and Ms. Shrestha Raychaudhuri ${ }^{2}$.

1. Assistant Professor And Head of Department of Management Studies, Rajiv Gandhi Institute Of Petroleum Technology, Jais district, UP, India

2. B.Tech, MBA Student, Rajiv Gandhi Institute Of Petroleum Technology, Jais district, UP, India. Life Member of ISCA.

\section{Manuscript Info}

Manuscript History

Received: 30 October 2016

Final Accepted: 29 November 2016

Published: December 2016

\section{Abstract}

The Agricultural Sector occupies a pivotal position in the Indian Economy. We simply cannot survive without food, and therefore, without Agriculture. Energy is an essential component of Agricultural production. It fuels the equipment, irrigates the crops, fertilizes the soil, sustains the live stock, transports the food, and processes the food into its final forms. As the population continues to grow, more agricultural production is required to support the increased food demand. At the same time, Energy and Environmental constraint mandate that agricultural production be accomplished effectively with minimal Energy consumption. It is necessary to increase agricultural yield per unit area of land, while preserving the soil integrity and Environment. Efficient Energy Management practices will help to achieve and maintain the delicate balance. To tackle energy security, to implement India's climate commitments, as well as to ensure food security and deal with water challenges, India must consider energy efficiency in Agricultural Sector. This paper deals with various challenges and wide variety of Energy efficient opportunities as related to sustainable Agriculture and Environment.

Copy Right, IJAR, 2016,. All rights reserved.

\section{Introduction:-}

Traditionally India has been predominantly an Agricultural Economy. Agricultural sector provides employment to about 54\% of total work force and contribute around 14\% of GDP. Agricultural Sector is a vital element for the inclusive and sustainable growth of the Indian Economy. Agricultural land accounts for around $40 \%$ of Total Geographical Area of the Country. Though the share of Agriculture in Total GDP have been falling (55\% in 195051 to $14 \%$ in 2014-15), India has been able to achieve self-sufficiency in meeting its food demand. Food grain production from 1950-51 to 2014-15 increased at 2.5\% per annum (from about 51 MMT in 1950-51 to 252 MMT in 2014-15), while population has increased at about $2 \%$ per annum during the same period, resulting in selfsufficiency in food grains.

The traditional Agricultural tools and implements relied mostly on human and animal power and used a negligible amount of commercial energy. Firm mechanization helps in the effective utilization of inputs to increase the productivity of Land and Labour. The share of muscle power in Agriculture has decreased from 90\% in 1950/51 to around $14 \%$ at current level. Increased investment in irrigation, infrastructure, expansion of credit, processing 
facilities etc. lead to a significant increase in the use of Modern Inputs. As a result of this crop production and rural agro processing emerged as a major consumer of commercial energy. Further, the increased commercialization of Indian Agriculture will require higher level of Energy input in Agriculture. Land preparation, harvesting and irrigation activities consumed most of the energy used in Agriculture. Tractors and lift irrigation pumps are two major areas of Energy consumption in Agricultural sector. Use of Tractors per 1000 ha of area harvested for cereals have increased from 12 in 1995 to 20 at present level.

India is having $18 \%$ of the World population and only $2.4 \%$ of World Surface Area. Further, India is having only $0.4 \%$ of World's Proven Petro Reserve. We meet only $22 \%$ of our crude oil requirement indigenously resulting on dependency on import. This makes Agricultural Sector very challenging from Energy perspective.

\section{Energy Scenario in Agriculture:-}

Direct Energy used in Agriculture is HSD \& Electricity. This is used mainly in Tractors, Lift Irrigation Pumps, Other Stationery / Equipment to prepare field, Plant and Harvest Crops, Transportation, etc. Indirect Energy is the energy consumed for manufacture of Inputs, such as Fertilizers \& Pesticides. The Fertilizer Industry is one of the largest consumers of primary commercial energy source.

Diesel and Electricity are the two main sources of Direct Commercial Energy in Agricultural sector.

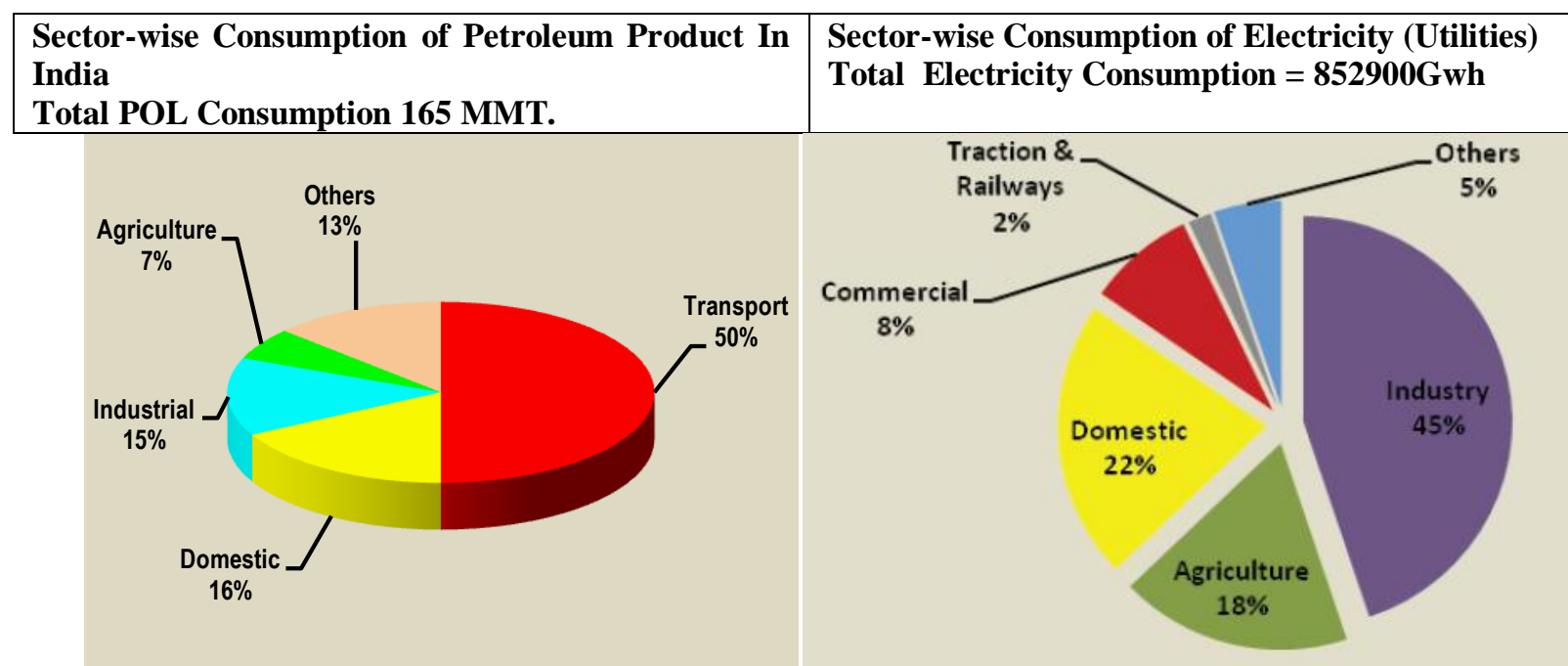

Agriculture Sector consumes around 11 MMT which is $7 \%$ of Total Petroleum products and $15 \%$ of total HSD consumption. Agriculture Sector consumes around $153522 \mathrm{Gwh}$ of Electricity which is $18 \%$ of Total Electricity Consumption. The preference of Electricity as an input has been growing in Indian Agriculture, specially for energizing irrigation pump sets.

Energy cost in production of major crops:-

Average Energy cost is more than $50 \%$ of production cost of major crops in India.

\begin{tabular}{|l|c|c|}
\hline & Share of energy in production cost of major crops in india \\
\hline Crop & Production cost (rs/ha) & Energy cost (rs./ha) \\
\hline Rice & $\mathbf{2 3 , 0 8 0}$ & $\mathbf{1 3 , 5 2 9}(\mathbf{5 9 \%})$ \\
\hline Wheat & $\mathbf{2 4 , 1 9 3}$ & $\mathbf{1 1 , 5 6 5 ( 4 8 \% )}$ \\
\hline Maize & $\mathbf{1 6 , 3 5 1}$ & $\mathbf{1 0 , 0 3 1 ( 6 1 \% )}$ \\
\hline Bajra & $\mathbf{1 0 , 5 3 8}$ & $\mathbf{6 , 6 7 8}(\mathbf{6 3 \%})$ \\
\hline Arhar & $\mathbf{1 4 , 4 7 3}$ & $\mathbf{7 , 2 4 1 ( 5 0 \% )}$ \\
\hline Potato & $\mathbf{5 5 , 1 8 5}$ & $\mathbf{3 7 , 7 4 3 ( 6 8 \% )}$ \\
\hline Sugarcane & $\mathbf{5 6 , 2 5 6}$ & $\mathbf{2 9 , 7 2 3 ( 5 3 \% )}$ \\
\hline
\end{tabular}

Tractors and Pump Sets are lifeline of Indian Agriculture:-

In Agricultural Sector major energy is consumed for operating Tractors and Pumping Water Activities. 


\section{Tractors:-}

Tractors form an integral part of farm mechanization and have a crucial role to play in increasing agricultural productivity. Tractor is a highly versatile piece of machinery having a multitude of uses, used in Agriculture both for land reclamation and for carrying out various type of crop cultivation and its processing. Use of Tractors has risen significantly over the years. In the year 1950 the use of Tractor / TH-Hectre was only 1 which has now risen to 20. The sale of Power Tillers also increased significantly over the years. Rapid mechanization of Agriculture will increase numbers of Tractors \& Power Tillers further in the coming decades.

\begin{tabular}{|l|l|c|}
\hline EQUIPMENT IN USE & YEAR 2013 & YEAR 2030(EST) \\
\hline TRACTORS AND POWER TILLERS & 4.5 MILLION & 16.4 MILLION \\
\hline
\end{tabular}

It is expected that there is threefold increase in HSD consumption in Tractors from present level by the year 2030.

\section{Pumping System:-}

In late 1960's when monsoon failed for consecutive years, use of Pump Set in Indian Agriculture began, resulting in significant increase of Energy Consumption. Presently, 1.8 Crs. Pump Sets are in operation. The Consumption of Electricity has raised from 18 Thousand GWh in 1983 to 1.6 Lakhs GWh at present. For energizing irrigation Pump Sets electricity has been growing in significance as a preferred energy input in Indian Agriculture. Increase of Electricity Consumption in Indian Agriculture is supported by the fact that Power Supply to the farm Sector is highly subsidized.

Managing agricultural load is increasingly becoming a challenge for electricity utility in India. Subsidized tariff generate a perception of zero marginal cost of electricity use and consequently, efficiency in consumption is disregarded. Upgrading of existing pumping systems presents an immediate need and an unprecedented opportunity. Implementation of this program is crucial as energy bills for agricultural pump sets are being paid by Govt. in the form of subsidy. Low or free electricity coupled with high inefficiencies contributes to adoption of local made inefficient \& unreliable pump sets, results in massive water wastage $\&$ higher energy consumption. The average efficiency of existing in-efficient pump sets is in the range of $20 \%-30 \%$ whereas efficiency range of new star rated Energy Efficient Pump sets (EEPS) is $40 \%$ - 50\%. Therefore, there is a need to tap the huge energy savings potential promised in agriculture pumping sector. Efficient irrigation pumps, including variable speed pump motors; Frequent management/maintenance of irrigation systems; Proper pump-sizing; and Upgrade to more efficient irrigation is some of the important areas in pumping system.

\section{Why Energy Efficiency is needed In Agriculture:-}

There are increasing trends towards commercialization and diversification of Agriculture.

Livestock, Horticulture, Fisheries and Poultry Sectors are growing rapidly. There is increasing inclination towards the use of modern inputs and farm mechanization. These developments have significant implications for energy use in agriculture. Modern inputs and mechanization require more commercial energy and this hold true for the management of the perishable commodities also. This implies a significant change in energy-use pattern in the Indian Agriculture. Energy Trends in the Indian Agriculture is ever increasing; therefore improvement in Energy Efficiency is the need of the hour.

\section{Energy Savings Areas for Tractors:-}

By proper maintenance, operation \& running there is a scope of substantial savings of Diesel in Tractors. Some of effected tips are appended below:

Proper maintenance is a must. It is proven that badly maintained tractor waste upto $20 \%$ Diesel.

Keeping the Tractor in good operating condition by following the operating \& maintenance manual of tractor. Such measures not only save the fuel but also prolong the life of Tractor

Worn out tiers reduces the power of tractor thus fuel wastage $20 \%$ less air pressure leads to $3 \%$ loss of fuel.

Dust is the enemy of Engine. Unfiltered air causes 45 times faster wear in cylinder liner and 115 times faster wear of piston rings. Clogged air filters increase fuel consumption by $10 \%$. 
Excess smoke means fuel wastage, it could be due to overloading or driving in wrong gear. If smoke persists, get the tractor serviced overall.

\section{Energy Challenges In Pump Sets:-}

India is having around 20 million Agricultural Pump sets. These Pump sets consume around $1.6 \mathrm{GWh}$ which is $18 \%$ of total electricity consumption. Electricity Supply is free or applicable tariff is very low. Market is dominated by inefficient pump sets at a cheaper cost efficient pump sets are available at a higher cost. To save energy in the pump set, proper installation and operation \& maintenance manual guidelines to be followed. BIS marked Foot Valve with wide mouth, use of large diameter PVC or HDPE pipe, less no. of bends and fittings in pump sets is necessary.

\section{Conclusion:-}

Energy efficiency in Agriculture is mainly driven by farmers, their goals and their business philosophy. This in turn is determined to a large extent by cost-price relationships and their impact on farmer's income and welfare. Education and access to information is important to create an awareness of energy efficiency. The economic and political environment was detected as main external drivers for energy efficiency in agriculture.

Requirement of energy per Hectare by Indian farmers is 3.7 times of Japan, 1.55 times of US, 1.47 times of Asian Avg. \& 1.5 times of World Avg. Demand for commercial energy in Agriculture will increase due to mechanization / commercialization of Indian Agriculture. Further the demand for food, feed \& fiber is increasing all over the World. However there is a tremendous scope of improvement in Energy Efficiency in Agricultural Sector in totality and thereby reduction of Green House Gases. Proper irrigation scheduling, Effective irrigation technique, Effective crop management practice, improvement in water use efficiency are some of the areas of improvement in efficiency gain in Agriculture. Further improvement in Tractor \& Pump Set operation, implementation of Star labeled Mono Set Pumps, Demand side management to reduce power consumption, improvement in ground water extraction efficiency is essential in Agricultural Sector for improvement in Energy Efficiency \& reduction of Green House Gases.

\section{Reference:-}

1. TERI : Teddy 2014-15

2. Ministry of Agriculture, Govt. of India, Annual Report

3. Ministry of Power, Govt. of India Annual Report

4. Ministry of Petroleum \& Natural Gas Govt. of India, Basic Statistics

5. Ministry of Statistics \& Program Implementation - Energy Statistics

6. Petroleum Conservation Research Association - Fuel Savings Tips for Tractors \& LIP

7. Bureau of Energy Efficiency, Agricultural Demand Management 